1 Nausieda PA. Sydenham's chorea, chorea gravidarum and contraceptive-induced chorea. Handbook of clinical neurology, vol 5(49) Extrapyramidal disorders. Amsterdam: Elsevier, trapyramidal

2 Padberg GW, Bruyn GW. Chorea - differential diagnosis. In: Vinken PJ, Bruyn GW, Klawans HL, eds. Handbook of clinical neurology, vol 5(49) Extrapyramidal disorders. Amsterdam: Elsevier, 1986:549-64.

3 Husby G, van de Rijn I, Zabriskie JB, Abdin $\mathrm{ZH}$, Williams RC. Antibodies reacting with cytoplasm of subthalamic and caudate nuclei neurons in chorea and acute rheumatic fever. f Exp Med 1976;144:1094-110.

4 Schwarz GA, Barrows LJ. Hemiballism without involvement of Luy's body. Arch Neurol 1960;2:420-34.

5 Buruma OJS, Lakke JPWF. Ballism. In: Vinken PJ, Bruyn GW, Klawans HL, eds. Handbook of clinical neurology, vol 5(49) Extrapyramidal of clinical neurology, vol 5(49) Extrapyramidal
disorders. Amsterdam: Elsevier, 1986: 369-80.

\section{Cervical spinal extradural haematoma causing a transient Brown-Sequard syndrome}

Extradural haematomas of the spinal canal are uncommon. They may be traumatic or occur spontaneously. Spontaneous recovery is exceptional. We report an extradural haematoma of the cervical spinal canal, precipitated by trauma, which resulted in a transient Brown-Sequard syndrome.

A previously fit 20 year old man developed an extradural haematoma in his cervical spinal canal after an episode of "disco dancing" and "head banging". The following day he complained of neck pain, and 36 hours after this, he presented to hospital complaining of weakness of his left arm and leg with sensory loss in his right leg. There was no previous history of trauma, neurological disease or bleeding disorder.

Physical examination on admission to hospital demonstrated a grade $2 / 5$ spastic weakness affecting the left side of the body below a level of C4. There was anaesthesia to pinprick below T8 on the right, and a right Horner's syndrome was noted. Bladder sensation and function were intact. Plain radiographs of the cervical spine were normal. A
CT scan of the cervical spine showed an extradural haematoma localised to the left side of the spinal canal between the levels of C4 and C6 (figure). Routine full blood count, film and clotting studies were normal.

The patient was treated with oral dexamethasone on admission and the neck immobilised in a cervical collar. The motor weakness improved over the subsequent 24 hours, followed by return of temperature sensation to the leg. Over the next three days the sensory level to pinprick sensation fell to the mid-lumbar dermatomes and then resolved completely. Steroid therapy was gradually withdrawn and the patient became ambulant without resurgence of his symptoms.

A Brown-Sequard pattern of dissociated sensory loss is extremely uncommon as a result of an extradural haematoma in the spinal canal. The first case was described in 1958 by Geuna and Pazni.' Since then a further four cases have been reported. ${ }^{2-5}$ These cases were all spontaneous haematomas occurring without preceding trauma. Two of these cases were associated with bleeding diatheses. ${ }^{45}$

Surgical intervention is advocated for most cases, especially when acute retention of urine has occurred. The cases of BrownSequard syndrome referred to were all associated with haematomas of the cervical canal, and all made good recoveries following decompressive laminectomy.

The case we have reported improved rapidly on steroids. By the time the patient had reached the Regional Neurological Centre in Newcastle, approximately 20 hours after first presenting to hospital, the neurological signs were receding. Conservative therapy was therefore continued and the patient made a complete recovery over the ensuing three days.

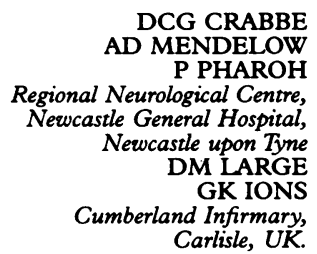

Correspondence to: Mr DCG Crabbe, Department of Pathology, The Royal Victoria Infirmary, Newcastle upon Tyne NE1 4LP

1 Geuna E, Pazni CA. Considerazioni se di un caso di compromissione midollasa da emotoma extradurale cronico. Rassegna Medica Sardinia 1958;60:645-9.

2 Segelov JN. Spinal epidural haematoma, a report of two cases. Pacific Medicine and Surgery 1967;75:169.

3 Russman BS, Kazi KH. Spinal epidural haematoma and the Brown-Sequard syndrome. Neurology (Minneapolis) 1971;21:1066-8.

4 Nattle H, Sieb JP, Rohner M, Mumenthaler M. Non-traumatic spinal epidural and subdural haematomata. Neurology 1987;37:1351-6.

5 Mustafa MH, Bernstein B. Spontaneous spinal epidural haematoma, Brown-Sequard syndrome and factor IX deficiency. Annals of Internal Medicine 1987;106:477-8.

Figure (A-left) Axial CT scan through C4 showing hyperdense right sided extradural haematoma in the spinal canal. (B-right) Axial CT scan through C5 (below) and sagittal reconstruction scan (above) demonstrating the length and posterior position of the extradural haematoma. 